\title{
Volatility clustering at the Johannesburg Stock Exchange: Investigation and Analysis
}

\section{Olivier Niyitegeka}

Regent Business School, Graduate Student

D.D.Tewari

Professor School of Accounting, Economic and Finance the College of Law and Management University of KwaZulu-Natal, Durban, South Africa. Email.davetewari@gmail.com

Doi:10.5901/mjss.2013.v4n14p621

\section{Abstract}

This paper examines the existence and the nature of the volatility clustering phenomenon in the Johannesburg Stock Exchange (JSE). Volatility clustering is one of the most common stylized facts in financial time series; this phenomenon has intrigued many researchers and oriented in a major way the development of stochastic models in finance. The study uses GARCH-type models to detect volatility clustering. GARCH-type models are widely used to test the volatility clustering phenomenon. Their popularity stems from their healing power for heteroskedasticity in regression models and their ability to model nonlinear dynamics. Various studies on volatility clustering suggest that negative shocks to stock prices will generate more volatility than positive shocks of equal magnitude. In this regard the study also examines the asymmetric effect of positive and negative shocks in the JSE. The results indicate the presence of volatility clustering in the JSE. An asymmetric effect of positive and negative shocks on conditional volatility could not be identified.

Keywords: Volatility clustering, leverage effect, GARCH, asymmetric GARCH models.

\section{Introduction}

Uncertainty plays a crucial role in financial theories. Many models in the field of academic finance use variance (or standard deviation) as a measure of uncertainty. In most of these models variance is assumed to be constant through time; this is known as homoscedasticity (Brooks, 2002: 386). However, empirical evidences have rejected this assumption. It has been established that time series exhibit volatility clustering, where calm and volatile episodes are observed, such that at least the variance appears to be predictable. Figure 1 represents the daily return of the FTSE/JSE's All Share Index, for a period of five years. This raw time series data suggests that there are periods of volatility clustering where days of large movement are followed by days with the same feature.

Figure.1. Daily returns for FTSE/JSE All Share Index during for the period between 10 August 2006 and 10 August 2011

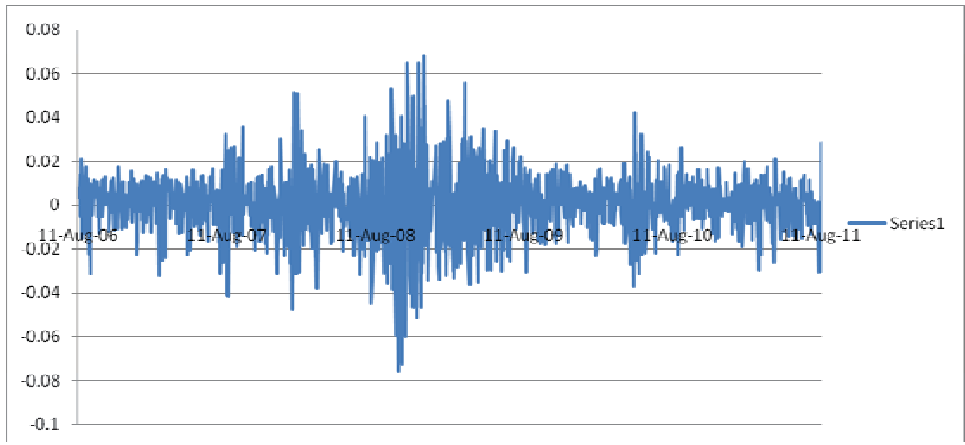

Source: McGregor BFA, 2012 
Statistically, volatility clustering entails a strong autocorrelation in squared returns. A technical term given to this phenomenon is Autoregressive Conditional Heteroskedasticity (ARCH) or simply the ARCH effect.

Modelling volatility is important when it comes to risk management and portfolio selection as well as pricing of assets. Volatility makes investors more averse to holding stocks due to uncertainty; investors in turn demand a higher risk premium to insure against the increased uncertainty. A greater risk premium results in a higher cost of capital, which subsequently leads to less private investment (Emenike, 2010). Therefore, modelling volatility improves the usefulness of measuring the intrinsic value of securities and in the process it becomes easy for a firm to raise funds in the market. Additionally, the detection of volatility provides an insight for a better way to design an appropriate investment strategy (Emenike, 2010). On the basis of the aforementioned, it is essential to know the behaviour of volatility of the Johannesburg Stock Exchange (JSE) returns. This paper adds to the existing literature on the persistence of market return volatility at the JSE. Previous studies by Samouilhan (2007) and Louw (2008), found that volatility clustering is present clustering on the FTSE/JSE top 40 index. This study broadens the analysis by examining volatility in the South African stock exchange using the FTSE/JSE All Share Index (ALSI) as a proxy for the entire shares listed on the South African stock market.

The study is organised as follows: Section Two provides a brief review of the relevant literature on volatility clustering. Section Three covers data and methodology. Section Four provides a discussion of the empirical findings, and Section Five concludes.

\section{Volatility Clustering: A Review}

As mentioned above, empirical research has provided strong evidence that volatility is time-varying and that changes in volatility are predictable to some extent. A ground-breaking study by Mandelbrot (1963), and later confirmed by Fama (1965), found that there is a memory effect the size of price change. Large price changes were followed by large price changes of either sign, or that small price changes where followed by small prices changes of either sign. Another study by Christie (1982) established that, owing to financial leverage, there is a negative relationship between the volatility of the rate of return on equity and the value of equity. This meant that an increase in financial leverage was accompanied by an increase in volatility (Louw, 2008). Christie's (1982) findings were in sharp contrast with Black's (1976) results that indicated that positive and bad news had a symmetrical impact on volatility (Louw, 2008).

An easy method for detecting volatility clustering is to capture changing variance using Autoregressive Conditional Heteroskedasticity (ARCH) and Generalized ARCH (GARCH), models developed by Engle (1982), and extended by Bollerslev (1986) and Nelson (1991).

Various studies investigated volatility clustering on financial markets using GARCH-type models, and include, among others, Jacobsen and Dannenburg (2003) who used temporal aggregation on monthly stock returns for daily, weekly, bi-weekly and monthly data from France, Germany, Italy, Netherlands, United Kingdom and the United States. They identified a significant GARCH effect at monthly levels, which was confirmed by a Monte Carlo simulation. Jagajeevan (2012) examined the persistence of volatility, risk-return trade off and asymmetric volatility in returns, on daily and monthly returns on the All Share Price Index of the Colombo stock exchange. He only identified volatility clustering in daily returns, but not in monthly returns. Jagajeevan (2012) also identifies a leverage effect in daily returns, where the stock market becomes more volatile when negative shock takes place as compared the positive shock.

By using agent-based models ${ }^{1}$, academics have established that agents' herd behaviour ${ }^{2}$ causes volatility clustering in stock markets. For instance, Alfarano and Lux (2001) noted that the existence of herd behaviour among market participants modifies the distribution of market returns. As they explained further, this is characterized by the presence of fat tails and volatility clustering in these financial data. Yamamoto (2011) used an agent-based model to run simulations on an artificial stock market. The simulations consisted of two economies: one with and the other without herding. He established that a herding economy can engender volatility clustering, but volatility could be found when agents do not herd others at all. Park (2008) demonstrated that herd behaviour leads to a high increase in volatility but not trading volume.

As far as African stock markets are concerned, a considerable number of studies investigated volatility clustering. Emenike (2010) investigated volatility clustering, leptokurtosis and leverage effect for the Nigerian Stock Exchange returns series. Using GARCH $(1,1)$ he found that volatility of stock returns is persistent in Nigeria. Using the GJR-GARCH

${ }^{1}$ Computer simulation that represents individual actors in a dynamic social system.

${ }^{2}$ Herd behaviour occurs when managers simply mimic the investment decision of other managers, ignoring substantive private information. 
$(1,1)$ model he also identified leverage effects in Nigerian stock returns. A study by Floros (2008) examined volatility in the Egyptian stock market using daily data for Egypt's CMA general index. Using GARCH -type models, he found strong evidence of volatility clustering. He also noted that a leverage effect exists and that bad news increased volatility. A study by Samouilhan (2007) found a large degree of persistence of volatility on equity returns on the JSE for the broad ALSI40 index and its various sub-sectors. Using a Component ARCH (CARCH) model, he found significant evidence of volatility clustering over both the long and the short run for each series and for the broad index. Louw (2008) examined volatility clustering on the FTSE/JSE top 40 index. He used various models to test the phenomenon, namely, linear regression, exponential smoothing, $\operatorname{GARCH}(1,1)$ and $\operatorname{EGARCH}(1,1)$. After conducting an analysis of the distribution qualities, the autocorrelation of volatility for five return intervals, as well as the results of forecasting models, he found sufficient evidence that volatility clustering exists on the FTSE/JSE top 40 index. He also concluded that more complex models, such as GARCH $(1,1)$ and EGARCH(1,1), marginally outperform less complex models. Ahmed and Suliman (2011) used both symmetric and asymmetric GARCH models to investigate conditional variance in daily returns of the Khartoum Stock Exchange (KSE). They found a high degree of persistence in the conditional volatility of stock returns on the KSE.

\section{Data and Methodology}

\subsection{Data}

In this study, daily returns based on closing prices of the FTSE/JSE All Share Index for the period between August 2006 and August 2011 was used. They represent 1250 observations. The data was downloaded from database of McGregor BFA.

Table 1 presents descriptive statistics for the series, they are: sample means, standard deviations, skewness, kurtosis and the Jarque-Bera test for normality (with their $p$-value). It is clear that the distribution of the series is nonnormal and has leptokurtic distribution, features that are common with most financial data (Chinzara, 2008).

Table 1. Descriptive statistics for the log return of FTSE/JSE All Share Index

\begin{tabular}{|l|l|c|c|c|c|c|c|c|}
\hline Number of observation & mean & Median & Minimum & Maximum & Standard deviation & Skewness & Kutosis & Jarque-Bera \\
\hline 1250 & 0.012 & 0.0465 & -3.292 & 2.968 & 0.651 & -0.121 & 140.639 & $404^{\star \star \star}$ \\
\hline
\end{tabular}

\subsection{Methodology}

The study uses a Generalised Autoregressive Conditional Heteroskedasticity (GARCH) type model to test volatility clustering. As mentioned above, the GARCH models are widely used to test the volatility clustering phenomenon. Their popularity stems from their healing power for heteroskedasticity in regression models and their ability to model nonlinear dynamics (Hourvouliades, 2007).

The GARCH model, employs the maximum likelihood procedure, and allows the conditional variance to be dependent upon previous own lags. The conditional variance equation is expressed as follows:

$$
\sigma_{t}^{2}=\alpha_{0}+\sum_{J=1}^{P} \beta \sigma_{t-1}^{2}+\sum_{i=1}^{q} \alpha_{1} \varepsilon_{t-1}^{2}
$$

where $\alpha_{0}$ is a constant term, $\sigma_{t}^{2}$ is the volatility at time $t, \varepsilon_{t-1}^{2}$ is previous period's squared the error term, and $\sigma_{t-1}^{2}$ is the previous period's volatility. For any $\operatorname{GARCH}(p, q)$, the order is normally chosen through the Schwarz Bayesian Information Criteria (SBIC) and is based on the following formula:

$$
S B I C=1+\ln (2 \pi)+\ln \left(\frac{E S S}{T}\right)+\frac{k}{T}(\ln T)
$$

where $T$ is the sample size, $k$ is the number of estimated parameters and ESS is the sum of the squared residuals in the regression. The SBIC is usually chosen over the Akaike Information Criterion (AIC) because it penalizes more heavily for degrees of freedom, therefore, it tends to select more parsimonious models. The model with the smallest criterion value for each GARCH specification is used (Chinzara, Azakpioko, 2009).

Interestingly enough, first-order GARCH models, that is, GARCH $(1,1)$ models, are so often empirically adequate 
to test volatility clustering that they have achieved something of a canonical status (Diebold, 2012) .

\subsubsection{GARCH $(1,1)$}

Working under the assumption that volatility depends on the last period's conditional volatility, the GARCH $(1,1)$ model is expressed as follows:

$$
\begin{aligned}
& Y=\mu_{t}+\varepsilon \\
& \sigma_{t}^{2}=\alpha_{0}+\alpha_{1} \varepsilon_{t-1}^{2}+\beta \sigma_{t-1}^{2}
\end{aligned}
$$

Where Equation 3 is the mean equation and Equation 4 is the conditional variance equation, $\alpha_{0}$ is a constant term, $\sigma_{t}^{2}$ is the volatility at time $t, \varepsilon_{t-1}^{2}$ is previous period's squared the error term, and $\sigma_{t-1}^{2}$ is the previous period's volatility. Statistically significant positive parameter estimates $\alpha_{1}$ and $\beta$ (with the constraint $\alpha_{1}+\beta<1$ ) would indicate the presence of clustering, with the rate of persistence expressed by how closer $\alpha_{1}+\beta$ is to unity, the bigger the persistence of conditional volatility.

The constraint $\alpha_{1}+\beta<1$ allows the process to remain stationary, with the upper limit of $\alpha_{1}+\beta=1$ which represents an integrated process.

It should be noted that a key feature for an appropriate mean Equation 3 is that it should be "white noisy" meaning that its error terms should be serially uncorrelated. In this regard the mean Equation 3 will have to be tested for autocorrelation using the Durbin Watson (DW) test and the LM autocorrelation test. Should there be evidence of autocorrelation, lagged values of the dependent variable will be added to the right-hand side of Equation 4 until serial correlation is eliminated (Chinzara, Azakpioko, 2009). The appropriate mean equation will also be tested for ARCH effect to ensure that it is necessary to proceed to estimating GARCH models.

The GARCH $(1,1)$ model assumes that good and bad news have a symmetrical effect on volatility and this is not always the case in various financial time-series. In this regard, the study estimated EGARCH and GJR GARCH models.

\subsubsection{GJR GARCH $(1,1,1)$}

The GJR GRCH model is a simple extension of GARCH with the additional term added to account for possible asymmetries. The conditional variance is given by:

$$
\sigma_{t}^{2}=\alpha_{0}+\alpha_{1} \varepsilon_{t-1}^{2}+\beta \sigma_{t-1}^{2}+\gamma \mu_{t-1}^{2}+I_{t-1}
$$

where $I_{t-1}=1$ if $\mu_{t-1<0}^{2}$ and $I_{t-1}=1$ otherwise.

$I$ is the asymmetry component and $\gamma$ is the asymmetry coefficient. The presence of leverage effects is indicated by significantly positive $\gamma$. The idea behind this is that good news $\left(\varepsilon_{t}>0\right)$ and bad news $\left(\varepsilon_{t}<0\right)$ will have different impacts on conditional variance. Good news will have an impact of $\alpha_{1}$, bad news will have an impact of $\alpha_{1} \gamma$. Thus, if $\gamma$ is significantly different from zero, the impact of good news is different from the impact of bad news on current volatility (Arguile, 2012). It is worth noting that the condition for non-negativity will be $\alpha_{0} \geq 0, \alpha_{1} \geq 0, \beta \geq 0$, and $\alpha_{1}+\beta$.

\subsection{3 $\operatorname{EGARCH}(1,1,1)$}

Another GARCH model that accounts for an asymmetric affect is Exponential GARCH $(1,1,1)$ (EGARCH). It is expressed as follows:

$$
\ln \left(\sigma_{t}^{2}\right)=\alpha_{0}+\alpha_{1}\left(\frac{\left|\varepsilon_{t-1}\right|}{\sigma_{t-1}}-\sqrt{\frac{2}{\pi}}\right)+\beta \ln \left(\sigma_{t-1}^{2}\right)+\gamma \frac{\varepsilon_{t-1}}{\sigma_{t-1}} .
$$

Where $\alpha_{1}$ and $\beta$ are still interpreted as they are in the $\operatorname{GARCH}(1,1)$ model and $\gamma$ is the asymmetry coefficient. The 
inclusion standardized residual $\frac{\varepsilon_{t-1}}{\sigma_{t-1}}$ allows the EGARCH model to be asymmetric for $\gamma \neq 0$. This is captured by the fact that the ARCH effect represented by $\alpha_{1}+\gamma$ will be obtained for positive residuals and the ARCH effect represented by $\gamma-\alpha$ will be obtained for negative residuals. In other words, the leverage effect, which is a special case of asymmetric impacts, would exist if $\gamma<0$ (Chinzara, 2008).

\section{Results and Analysis}

Before running GARCH-type models, the mean equation was estimated and tested for autocorrelation for FTSE/ ALSI index and ARCH effect. The results are reported in Table 2.

Table 2: Test for autocorrelation and ARCH effects

\begin{tabular}{|c|c|c|}
\hline & DW stat test & Arch LM test \\
\hline ALSI & 1.92 & $45.230[0.000]^{\star \star *}$ \\
\hline
\end{tabular}

***, ** and * indicate significance at the $1 \%, 5 \%$ and $10 \%$ levels respectively.

The result of the DW stat test is 1.92 implying that there is no evidence of autocorrelation in the mean equation. It is also clear that ALSI shows significant evidence of the ARCH effect, implying that the mean equation did not adequately capture volatility, hence we estimate the GARCH models based on this mean equation.

GARCH(1,1), EGARCH $(1,1,1)$ and GJR GARCH $(1,1,1,1)$ are therefore estimated and the results are reported in Table 3

Table 3. Testing for volatility clustering

\begin{tabular}{|c|c|c|c|}
\hline & GARCH(1,1) & EGARCH $(1,1,1)$ & GJR GARCH $(1,1,1)$ \\
\hline$\alpha_{0}$ & $0.0064^{\star \star *}$ & $-0.104^{\star \star \star}$ & $0.0063^{\star \star \star}$ \\
\hline$\alpha_{1}$ & $0.108^{\star \star \star}$ & $0.105^{\star \star *}$ & 0.031 \\
\hline$\beta$ & $0.876^{\star \star \star}$ & $0.982^{\star \star *}$ & $0.906^{\star \star \star}$ \\
\hline$\alpha_{1}+\beta$ & 0.984 & 1.807 & 0.937 \\
\hline $\mathrm{Y}$ & $\mathrm{n} / \mathrm{a}$ & $-0.114^{\star \star \star}$ & 1.199 \\
\hline AIC & 2067.009 & 2027.480 & 2033.276 \\
\hline BIC & 2092.664 & 2035.196 & 2053.801 \\
\hline
\end{tabular}

***, ${ }^{* *}$ and $*$ indicate significance at the $1 \%, 5 \%$ and $10 \%$ levels respectively.

The sum of the $\alpha_{1}$ and $\beta$ coefficients is high in all models, indicating the presence of volatility clustering. For instance, in the GARCH model the sum of $\alpha_{1}+\beta$ is 0.984 indicates the presence of volatility clustering. In the EGARCH model, however, the stationarity condition $(\alpha+\beta<1)$ is violated, since the sum of $\alpha$ and $\beta$ is more than unity. For this reason, the EGARCH model should not be used to test the leverage effect. As for the GJR model, although the asymmetry coefficient is positive, it is not significant at conventional levels of significance. Given the fact that GJR GARCH and EGARCH could not reach conclusive results, we conclude that asymmetric effects of news on conditional volatility are not prevalent in the JSE.

\section{Conclusion}

This paper investigated the volatility of stock market returns in the JSE using three variants of the GARCH model, namely, $\operatorname{GARCH}(1,1) \operatorname{GJR} \operatorname{GARCH}(1,1,1)$ and $\operatorname{EGARCH}(1,1,1)$. Volatility clustering and leverage effects were examined for the JSE returns series from August 2006 to August 2011. The results from the GARCH $(1,1)$ model show that volatility of stock returns is persistent in South Africa. The result of EGARCH and GJR-GARCH $(1,1)$ fail to indicate the existence of leverage effects in South African stock returns. This is in line with Louw's (2008) work that acknowledged the presence of volatility clustering in the FTSE/JSE top 40 index. 


\section{References}

Alfarano, S. and Lux, T. (2001), "A minimal noise trader model with realistic time series properties". Economics Working Papers, Christian-Albrechts-University of Kiel, Department of Economics.

Arguile, W. P. (2012), Performance of defensive shares on the JSE during financial crisis: evidence from analysis of returns and volatility (Doctoral dissertation, Rhodes University).

Black, F. (1976), "Capital market equilibrium with restricted borrowing" The Journal of Business. 5(3): 444-455.

Bollerslev, T.( 1986), "Generalized Autoregressive Conditional Heteroskedasticity". Journal of Econometrics. 31, 307-327.

Brooks, C. (2002), Introductory Econometrics for Finance. Cambridge: Cambridge University Press.

Diebold, F. (2012), 100+ Years of Financial Risk Measurement and Management. University of Pennsylvania and NBER. Available from: http://www.ssc.upenn.edu/ fdiebold/papers/paper108/DieboldElgar.pdf [Accessed 12/12/2012]

Chinzara, Z. (2008), An empirical analysis of the long-run comovement, dynamic returns linkages and volatility transmission between the world major and the South African stock markets. Unpublished Masters thesis. Grahamstown: Rhodes University.

Chinzara, Z., and Aziakpono, M. J. (2009), "Dynamic returns linkages and volatility transmission between South African and world major stock markets". Journal of Studies in Economics and Econometrics, 33(3), 69-94.

Christie, A. A. (1982), "The stochastic behavior of common stock variances: Value, leverage and interest rate effects". Journal of financial Economics, 10(4), 407-432.

Emenike, Kalu O. (2010), Modelling stock returns volatility in Nigeria using GARCH Models. Published in: Proceeding of International Conference on Management and Enterprise Development, Ebitimi Banigo Auditorium, University of Port Harcourt - Nigeria, Vol. 1, No. 4 (10. February 2010): pp. 5-11.

Engle, R. F. (1982), "Autoregressive conditional Heteroskedasticity with estimates of the variance of United Kingdom inflation". Econometrica. 50, 987-1007.

Fama, E. F. (1965), "The behavior of stock-market prices". The journal of Business, 38(1), 34-105.

Floros, C. (2008), "Modeling volatility using GARCH models: Evidence from Egypt and Israel. Middle Eastern Finance and Economics, 2: $31-41$

Hourvouliades, N. L., (2007), "Volatility Clustering in the Greek Futures market: Curse or Blessing?" International Research Journal of Finance and Economics. 11, Available from: http://wwww.eurojournal[Accessed on 03/05/2011]

Jacobsen ,B. and Dannenburg, D. (2003), "Volatility clustering in monthly stock returns." Journal of Empirical Finance. 10(4): 479-503

Jagajeevan, S .(2012), Return Volatility and asymmetric news effect in Sri Lankan Stock Market. Staff Studies, 40(1), 37 -57

Louw, J.P (2008), Evidence of volatility clustering on the FTSE/JSE top 40 index. Masters dissertation. Stellenbosch: University of Stellenbosch.

Mandelbrot, B. (1963), "The Variation of Certain Speculative Prices," Journal of Business, 36, 394-419.

Nelson, D. B. (1991), "Conditional Heteroskedasticity in Asset returns: A new Approach". Econometrica, 59 (2): 347-370.

Park, B. J. (2008), Herd behavior and volatility in financial markets. In The 3rd International Conference on Asia-Pacific Financial Markets.

Samouilhan, N. (2007), The persistence of SA equity volatility: A Component ARCHperspective. Journal of the Study of Economics and Econometrics, 31(1): 99-117.

Yamamoto, R. (2011), "Volatility clustering and herding agents: does it matter what they observe?". Journal of Economic Interaction and Coordination. $6: 41-59$. 